Document downloaded from:

http://hdl.handle.net/10251/112962

This paper must be cited as:

Martorell Alsina, SS.; Sanchez Saez, F.; Villanueva López, JF.; Carlos Alberola, S. (2017). An extended BEPU approach integrating probabilistic assumptions on the availability of safety systems in deterministic safety analyses. Reliability Engineering \& System Safety. 167:474-483. doi:10.1016/j.ress.2017.06.020

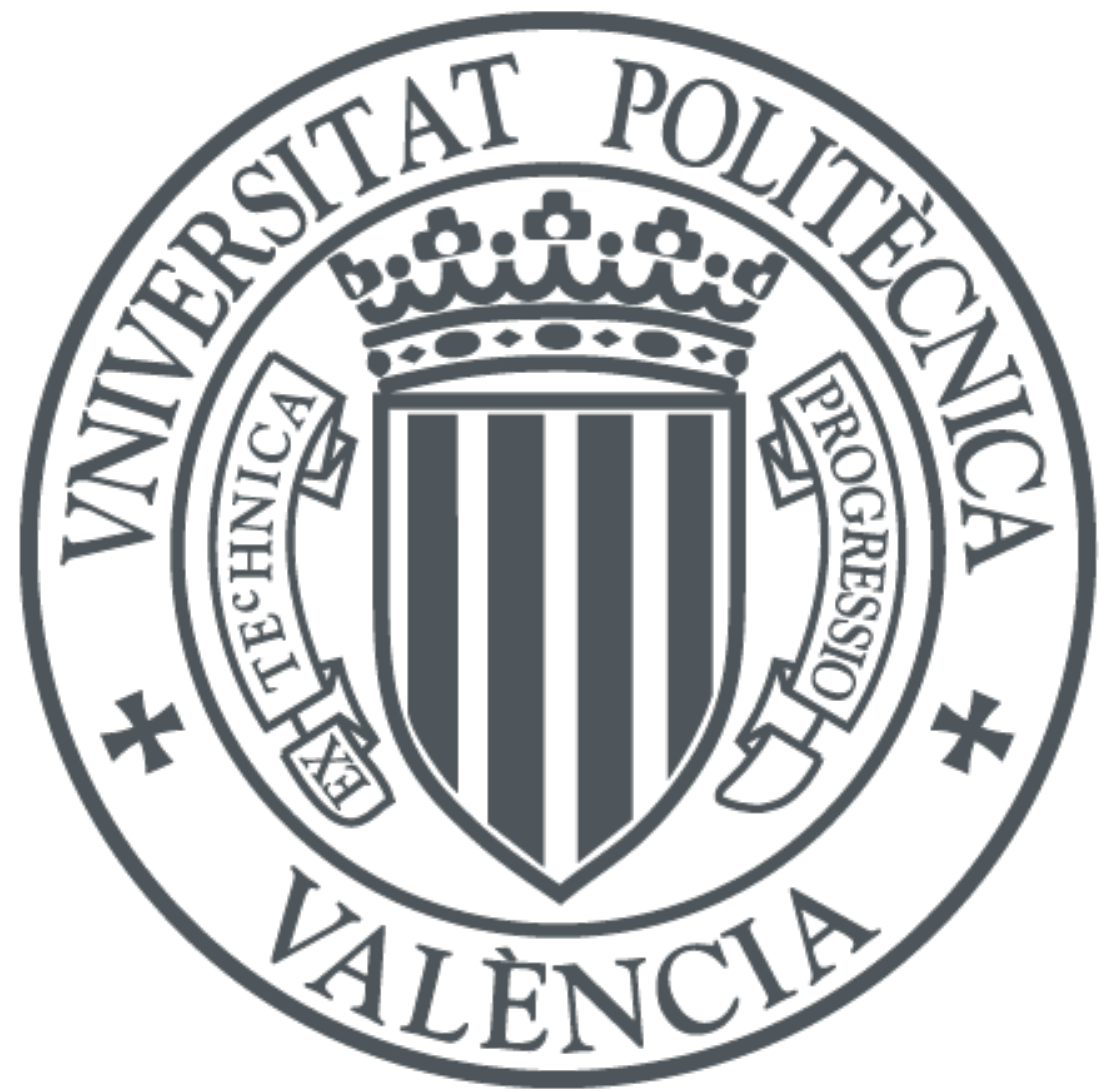

The final publication is available at

https://doi.org/10.1016/j.ress.2017.06.020

Copyright Elsevier

Additional Information 
An extended BEPU approach integrating probabilistic assumptions on the availability of safety systems in deterministic safety analyses

S. Martorell , F. Sánchez-Sáez, J.F. Villanueva, S. Carlos

PII: S0951-8320(17)30357-5

DOI: 10.1016/j.ress.2017.06.020

Reference: RESS 5887

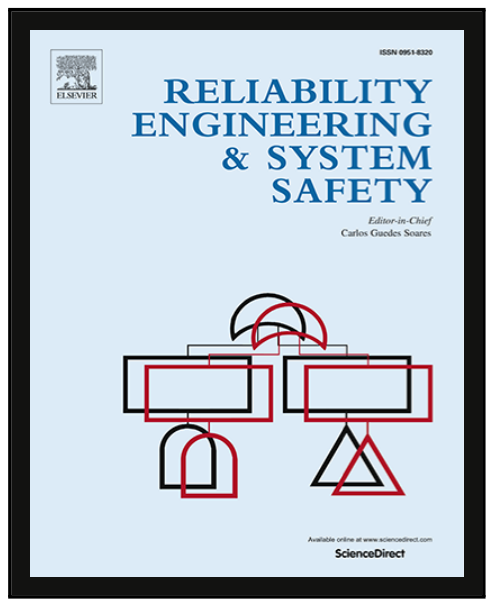

To appear in:

Reliability Engineering and System Safety

Received date:

25 March 2017

Revised date:

16 June 2017

Accepted date:

18 June 2017

Please cite this article as: S. Martorell , F. Sánchez-Sáez, J.F. Villanueva, S. Carlos , An extended BEPU approach integrating probabilistic assumptions on the availability of safety systems in deterministic safety analyses, Reliability Engineering and System Safety (2017), doi: 10.1016/j.ress.2017.06.020

This is a PDF file of an unedited manuscript that has been accepted for publication. As a service to our customers we are providing this early version of the manuscript. The manuscript will undergo copyediting, typesetting, and review of the resulting proof before it is published in its final form. Please note that during the production process errors may be discovered which could affect the content, and all legal disclaimers that apply to the journal pertain. 


\section{Highlights}

- Option 4 Deterministic Safety Analysis

- Best Estimate Plus Uncertainty (BEPU) methodology

- Extended BEPU

- Realistic safety systems configurations

- PSA-based configurations

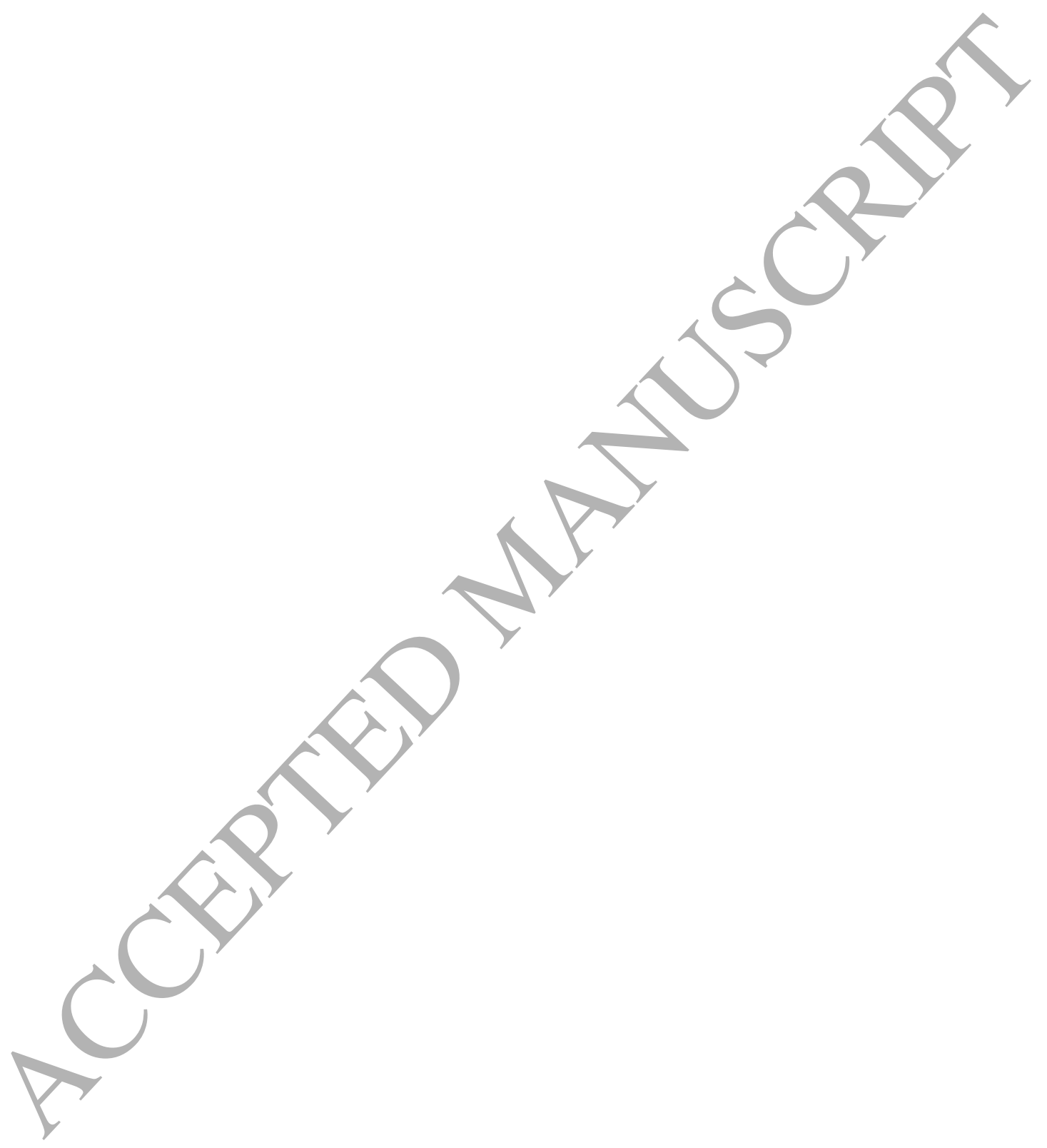




\title{
An extended BEPU approach integrating probabilistic assumptions on the availability of safety systems in deterministic safety analyses
}

\author{
S. Martorell*, F. Sánchez-Sáez, J.F. Villanueva, S. Carlos \\ MEDASEGI research group, Department of Chemical and Nuclear Engineering \\ Universitat Politècnica de Valéncia, Valencia, Spain \\ * Corresponding autor: S. Martorell (smartore@iqn.upv.es)
}

\begin{abstract}
The International Atomic Energy Agency (IAEA) produced guidance on the use of Deterministic Safety Analysis (DSA) for the design and licensing of Nuclear Power Plants (NPPs) in "DSA for NPP Specific Safety Guide, No. SSG-2", which proposes four options for the application of DSA. Option 3 involves the use of Best Estimate codes and data together with an evaluation of the uncertainties, the so called BEPU methodology. Several BEPU approaches have been developed in scopes that are accepted by the regulator authorities nowadays. They normally adopt conservative assumptions on the availability of safety systems. Option 4 goes beyond by pursuing the incorporation of realistic assumption on the availability of safety systems into the DSA. This paper proposes an Extended BEPU (EBEPU) approach that integrates insights from probabilistic safety analysis into a typical BEPU approach. There is an aim at combining the use of well-established BEPU methods and realistic ("probabilistic") assumptions on safety system availability. This paper presents the fundamentals of the EBEPU approach and the main results obtained for an example of application that focuses on an accident scenario corresponding to the initiating event "Loss of Feed Water (LOFW)" for a typical three-loops Pressurized Water Reactor (PWR) NPP.
\end{abstract}

\section{KEYWORDS}

BEPU, EBEPU, PROBABILISTIC AND DETERMINISTIC SAFETY ANALYSIS, OPTION FOUR, REALISTIC CONFIGURATIONS, SAFETY SYSTEMS 


\section{LIST OF ACRONYMS}

\begin{tabular}{|c|c|}
\hline AFWS & Auxiliary Feed Water System \\
\hline ATWS & Anticipated Transient Without Scram \\
\hline $\mathrm{BE}$ & Best Estimate \\
\hline BEPU & Best Estimate Plus Uncertainty methodology \\
\hline $\mathrm{CD}$ & Core Damage \\
\hline $\mathrm{CHF}$ & Critical Heat Flux \\
\hline DBA & Design Basis Accidents \\
\hline $\mathrm{DBC}$ & Design Basis Conditions \\
\hline DEC & Design Extension Conditions \\
\hline DNBR & Departure from Nucleate Boiling Rate \\
\hline DSA & Deterministic Safety Analysis \\
\hline EBEPU & Extended BEPU methodology \\
\hline FB & Feed and Bleed \\
\hline FOM & Figure Of Merit \\
\hline FOS & First Order Statistics \\
\hline IAEA & International Atomic Energy Agency \\
\hline $\mathrm{IE}$ & Initiating Event \\
\hline IHI & High Pressure Injection system \\
\hline IHR & High Pressure Injection system \\
\hline LOFW & Loss of Feed Water initiati \\
\hline MCS & Minimal Cut Set \\
\hline MFW & Main Feed Water System \\
\hline MSIV & Main Steam Isolation Val \\
\hline NPP & Nuclear Power Plant \\
\hline OS & Order Statistics \\
\hline PCT & Peak Cladding Temperature \\
\hline PDF & Probability Distribution Function \\
\hline PORV & Pressure Operated Relief Valve \\
\hline PRZ & Pressurizer \\
\hline PSA & Probabilistic Safety Analysis \\
\hline PWR & Pressurized Water Reactor \\
\hline RCS & Reactor Coolant System \\
\hline RPS & Reactor Protection System \\
\hline RV & Relief Valve \\
\hline SD & Steam-Dump valve \\
\hline SG & Steam Generator \\
\hline SSC & Specific Safety Guide \\
\hline STL & Standard Tolerance Level \\
\hline SSV & Secondary side Safety Valve \\
\hline SV & (Primary side) Safety Valve \\
\hline $\mathrm{TC}_{\mathrm{ij}}$ & Train/Component $j$ of Safety Function $i$ \\
\hline $\mathrm{TH}$ & Thermal Hydraulic \\
\hline
\end{tabular}




\section{INTRODUCTION}

Nowadays, regulators are concerned with the revision of current design license basis for operation of Nuclear Power Plants (NPPs) accounting for not only design basis conditions (DBC), such as anticipated occupational occurrences and design basis accidents (DBA), but also design extension conditions (DEC), both DEC without and with fuel damage, in a context where innovative approaches of safety assessment of current NPP are welcome.

The International Atomic Energy Agency (IAEA) guidance document "Safety Assessment for Facilities and Activities", General Safety Requirements No. GSR Part 4 (Rev. 1) [1], within the Requirement 15: Deterministic and probabilistic approaches, in requirement \#4.56, establishes that improvements in the overall approach to safety analysis have permitted a better integration of deterministic and probabilistic approaches. With increasing quality of models and data, it is possible to develop more realistic deterministic analysis and to make use of information from probabilistic analysis in selecting accident scenarios. Increasing emphasis is being placed on specifying how compliance with the deterministic safety criteria is to be demonstrated, for example, by specifying confidence intervals and specifying how safety margins are set. Some previous research aimed at developing methods for integrating deterministic and probabilistic safety assessment or even at developing an integrated safety assessment methodology [2-4].

In addition, the IAEA produced guidance on the use of deterministic safety analysis for the design and licensing of nuclear power plants (NPPs): "Deterministic Safety Analysis for Nuclear Power Plants Speeific Safety Guide," Specific Safety Guide No. SSG-2 [5], which is now under revision [6]. The SSG- 2 considers four options for the application of DSA. Option 4 , which is also called realistic deterministic safety analysis, is currently under research. An area of research in this context aims at developing methods for combining insights from probabilistic and deterministic safety analyses [7, 8]. The new methods, such as the one presented in [8], are intended to be used for safety assessment of some current NPP DBC, which includes anticipated occupational occurrences, also called DBC-2 (faults of moderate frequency), and DEC, both without and with significant fuel degradation, which are also called DEC-A and DEC-B accidents respectively. Option 4 is not intended for DBA within the design basis conditions, also divided into DBC-3 (infrequent faults) and DBC-4 (limiting faults), where it is proposed only the adoption of Options 1 to 3 (see section 2.15 in Ref. [6]). 
However, Option 3 involves the use of Best-Estimate Codes and data together with an evaluation of the uncertainties, the so called BEPU (Best Estimate Plus Uncertainty) methodology. Several BEPU approaches have been developed [9-16], some of them in scopes that are accepted by the regulator authorities nowadays. BEPU approaches focuses on an enveloping sequence representing a conservative progression of a DBA departing from an initiating event. Thus, for such an enveloping accidental sequence, it is adopted a conservative assumption on the availability of safety systems. Departing from this situation, Martorell et al., 2017 [17] proposed the adoption of more "realistic" assumptions, e.g. probabilistic assumptions, on safety systems availability. It presented a practical approach to identify relevant configurations of safety systems and to assess the associated occurrence probability of such configurations using PSA (Probabilistic Safety Analysis) results.

This paper proposes an Extended BEPU (EBEPU) approach that integrates insights from probabilistic safety analysis, such as the ones presented in Ref. [17], into a typical BEPU approach. There is an aim at combining the use of well-established BEPU methods and probabilistic ("realistic") assumptions on safety system availability. This novel EBEPU approach follows the principles of Option 4 of the above IAEA SSG-2 guide, which can be used for realistic deterministic safety analysis of current NPP designs [5, 6]. An example of application is provided to demonstrate how this approach performs. The case study focuses on an accident scenario corresponding to the initiating event "Loss Of Feed Water (LOFW)" for a typical three-loops Pressurized Water Reactor (PWR) NPP.

\section{EXTENDED BEPU APPROACH}

The novel EBEPU approach proposed in this paper merges a typical BEPU approach and PSA-based assumptions on the availability of safety systems, the later making use of the approach proposed in Martorell et al., 2017 [17]. Fig. 1 provides an overview of the EBEPU procedure. 


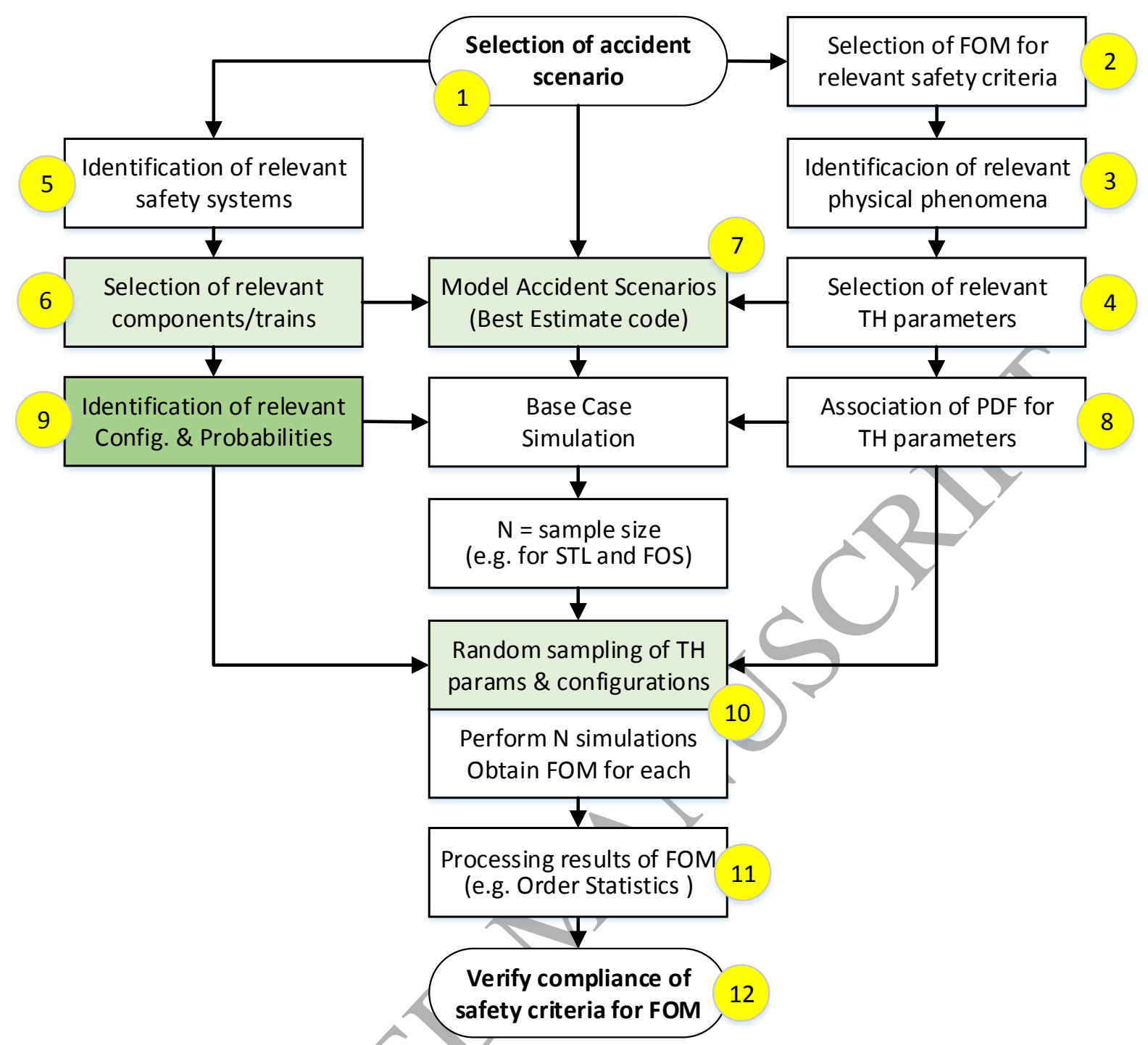

Figure 1. Overview of the EBEPU approach

The main difference between a typical BEPU and this EBEPU approach is the incorporation of step 9 to account for best estimate assumptions, i.e. PSA-based assumptions herein, on safety systems availability under the EBEPU approach. In addition, step 10 must be updated to account also for random sampling of safety systems configurations in addition to $\mathrm{TH}$ (Thermal Hydraulic) parameters. Moreover, the TH computer model must be developed in step 7 with appropriate level of detail at component/train in a coherent manner with step 6 in order to make it possible to address the particular configuration of the safety systems required for each TH simulation or computer run in step 10. BEPU approaches focuses only on an enveloping sequence representing a conservative progression of the accident scenario (step 1) departing from an initiating event. Thus, for such an enveloping accidental sequence, it is adopted a conservative assumption on the availability of safety systems (step 9). 
The EBEPU methodology consists of the following steps, most of which are common to standard BEPU methodology as said. First step corresponds to the selection of the accident scenario, e.g. an anticipated occupational occurrence DBC-2 or DEC accident.

Second step is the selection of the safety criteria linked to the accident scenario under study and the FOMs (Figures of Merit) involved in the acceptance criteria. As for BEPU method, the EBEPU approach involves simulation of a particular accident scenario using a BestEstimate code, which must provide an estimation of the evolution of relevant safety variables and their corresponding FOMs involved in the acceptance criteria of the DSA analysis. These FOM are usually extreme values of safety variables during the transient linked to the accident, e.g. critical heat flux (CHF), peak cladding temperature (PCT), etc. They describe the degree of challenge to the physical barriers that confines radioactivity in a NPP.

Next steps 3 and 4 include the identification and ranking of the relevant physical phenomena based on the safety criteria and the selection of the appropriate TH parameters affecting those phenomena, i.e. selection of TH parameters with significant impact on the plant response and this way with major influence on the simulation results, e.g. FOMs, of the accident scenario using the Best Estimate (BE) code.

Step 5 and 6 consist of the identification of relevant safety-related systems involved in the accident scenario and selection of relevant components/trains of the redundant safety systems that are responsible for performing the intended safety function to mitigate accident consequences.

Step 7 involves the development of the TH computer model of the accident scenario used for FOM simulation, e.g. input for TRACE Best Estimate code [18], with appropriate component/train detail and accounting for TH parameters coherently with steps 6 and 4 .

Step 8 consists of the association of $p d f$ for each selected TH parameter. BEPU approaches for the analysis of a particular accident assume the uncertainty in the safety outputs, i.e. FOMs, derives from the uncertainties in the inputs to the calculations (initial and boundary conditions) and those arising from the computational model. Current BEPU approaches mainly rely on a probabilistic description of the uncertainty in the relevant input parameters (step 4) and on the use of statistical techniques to estimate it, e.g. pdf. 
Step 9 comprises the identification of relevant, i.e. most probable, system configurations based on the availability of safety components/trains and association of a probability of occurrence for each configuration. Martorell et al., 2017 [17] presents a practical approach to identify relevant configurations of safety systems and to assess the associated occurrence probability of such configurations using PSA results of a NPP. The most relevant configurations mean the most probable ones according to PSA-based probabilistic models and data, which incorporate best estimate assumptions on the availability of safety systems.

Regulatory requirements impose acceptance criteria on above FOM, and the BEPU analysis must demonstrate compliance of FOM against acceptance criteria addressing the effect of uncertainties (step 12). Therefore, the development of a Base Case simulation using only mean values of TH parameters and components/trains configurations is not enough, although it is necessary for calibration purposes of the model and inputs to the Best Estimate code.

Most of BEPU approaches accepted by the regulatory authorities to verify compliance of safety criteria are based on propagation of input uncertainties (steps 8 and 9) through the model implemented into the BE code (step 7) and make use of Wilks'-based methods to determine the number of calculations of the safety outputs, i.e. FOMs, needed to verify compliance of acceptance criteria (step 12) with "standard tolerance levels (STL)", typically 95/95 in accordance with current regulatory practice. Accordingly, the value of the FOM that is compared with the corresponding acceptance criterion is often an upper or lower tolerance limit with level 95/95 instead of the FOM $p d f$. For example, it is often used one side tolerance interval of FOM based on the use Order Statistics (OS) of first order, i.e. FOS, with $\mathrm{STL}=95 / 95$, which requires a sample size of $\mathrm{N}=59$ runs [19].

The main advantage of using first order statistics (FOS) based on Wilks' formulae to derive the STL is that it provides always a conservative result with a few runs of the computer code. This way, the computational cost is kept practicable since the simulation of the evolution of the plant transient for each sample of inputs using complex TH (Thermal Hydraulic) models of NPP is very expensive in terms of computational cost. However, the use of higher order statistics, e.g. second and third order statistics, is also proposed, which involves both an increase of the sample size $(\mathrm{N})$ and an increase in the confidence of the coverage of the tolerance limit found [20]. 
Consequently, step 10 consist of, first, random sampling of the selected TH parameters and plant configurations. The TH parameters are sampled randomly form their $p d f$ without taking account their possible interactions as they are considered as independent parameters. For configurations, importance sampling is adopted using a pre-generated table of configurations and their associated probability, which has been obtained according to the procedure proposed in Ref. [17] that considers dependency among equipment configurations in a similar way as it is done in probabilistic safety assessment. The dependency between TH performance and system configurations is also considered. For example, let consider a given configuration in which a particular equipment is available. Even so, the equipment may be considered to be unavailable due to $\mathrm{TH}$ conditions imposed by the transient once the TH paremters have been sampled. Sample size (N) will depend on the particular statistical method and the acceptance criterion adopted to verify compliance of safety criteria. Second, it involves performing N computer runs to simulate the accident scenario and to obtain the FOMs for each run.

Next, step 11 consist of processing the results of the multiple computer runs $(\mathrm{N})$ to estimate either the probability distribution of the FOMs, or rather some descriptor of this distribution, such as for example a percentile of the FOM, or a tolerance level of each FOM with STL using OS, e.g. the FOS. Last step 12 involves to verify compliance of acceptance criterion for each FOM, e.g. with STL .

\section{EXAMPLE OF APPLICATION}

An example of application is provided to demonstrate how the EBEPU approach performs. The case study focuses on an accident scenario corresponding to the initiating event "Loss Of Feed Water (LOFW)'" for a typical three-loops Pressurized Water Reactor (PWR) NPP.

\subsection{Selection of the accident scenario}

The group LOFW includes those transients involving total loss of main feed water to steam generators (SG), which reduce water level of SG and consequently reduce their capacity to extract heat from the reactor coolant system (RCS). In particular, this group includes initiating events of category 16 and 24 in EPRI/NP-2230 [21].

Fig. 2 shows a typical event tree for the Initiating Event (IE) LOFW transient taken from the 
level 1 PSA available and the corresponding safety functions required following the occurrence of LOFW. It shows two alternative ways to remove heat from the RCS once the Reactor Protection System (RPS) is successful to shut down the NPP. One way involves the injection of water to SG by the Auxiliary Feed Water System (AFWS) and removal of heat through steam-dump valves (SD), relief valves (RV) or secondary side safety valves (SSV).

Eventually, in case of RCS pressurization, there may be a need to reduce pressure by means of the pressure operated relief valves (PORV), or primary side safety valves (SV) if required of the pressurizer (PRZ). Second alternative involves removing heat from the RCS by means of "Feed and Bleed" function, i.e. extracting warm water opening PORV valves manually and injecting cold water using the high-pressure injection system (IHI). In addition, it is needed re-circulation of water from the RCS using the same system under recirculation operational mode (IHR) in order to keep a safe operational state of the NPP in the long term.

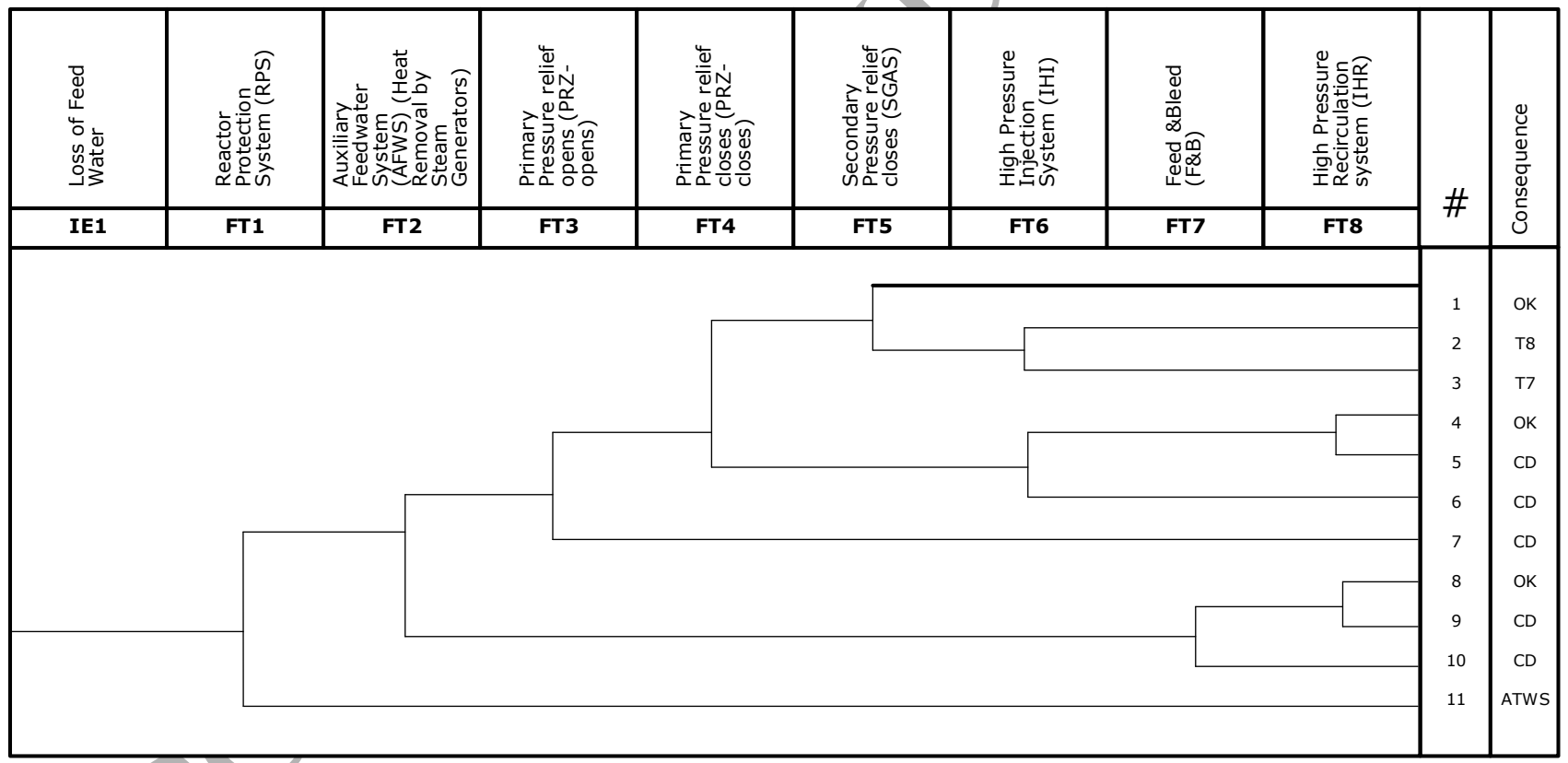

Figure 2. Event Tree for the LOFW transient

Fig. 2 shows several accidental sequences following the initiating event LOFW. For sake of simplicity in the application of the EBEPU methodology, sequence \#1 is the only one considered in the remaining of this case study (step 1). Other sequences may be studied in a similar way. Normally sequences ending with CD (core damage) are of interest for PSA, while those ending with OK, T7, T8 are of interest for DSA. Sequence ending with ATWS (Anticipated Transient Without Scram) requires further development using a secondary event 
tree. In this paper, sequence \#1 is of interest for DSA under the EBEPU approach.

\subsection{Safety criteria, FOMs and safety limits}

The document "Acceptance criteria and related safety margins" developed by the Task Group on CSNI Safety Margins Action Plan (SMAP) of the OECD/NEA [22] provides not only safety criteria and corresponding FOMs, but also an entire methodology to classify them into Categories according to plant states and transient frequencies.

The PSA available for this case study corresponds to a typical three-loop PWR NPP, which uses a frequency of the initiating event LOFW $\mathrm{F}(\mathrm{LOFW})=2,6610^{-1} \mathrm{r}^{-1} \mathrm{yr}^{-1}$. Based on this frequency, the initiating event LOFW belongs to Category 2 [22]. It also proposes several FOMs to represent the safety variables, their corresponding safety limits and acceptance criteria for Category 2, which address the multiple barriers supporting the NPP defense-indepth principle in order to guarantee the public safety. Táble 1 summarizes the FOMs, safety limits and acceptance criteria considered in this paper (step 2).

Table 1. Safety variables, FOMs and acceptance criteria for category 2 [22]

\begin{tabular}{llll} 
Barrier & $\begin{array}{l}\text { Safety } \\
\text { Variable }\end{array}$ & $\begin{array}{l}\text { Safety Parameter } \\
\text { (FOM) }\end{array}$ & $\begin{array}{l}\text { Acceptance Limit and Criteria } \\
\text { Category } 2\end{array}$ \\
\hline Fuel & CHF & DNB_MIN & 1.17 for $0 \%$ rods \\
\hline Fuel & FUELT & EUELT_MAX & $2863 \mathrm{~K}$ \\
\hline Primary & PRZP & PRZP_MAX & $100 \%$ design Pressure (18.9 MPa) \\
\hline Containment & CONTL & CONTL_MAX & $0.2 \%$ of primary inventory \\
\hline
\end{tabular}

The first barrier is the fuel and the safety variables proposed include the critical heat flux $(\mathrm{CHF})$ in the rods [23], the fuel temperature at the centerline of the rod (FUELT), and the peak cladding temperature (PCT). Related to the CHF, in this work the Departure from Nucleate Boiling Rate (DNBR) is calculated, which is the ratio of the heat flux needed to cause departure from nucleate boiling to the actual local heat flux of a fuel rod. This DNBR cannot be lower than 1.17 at $0 \%$ of the rods for category 2. Our FOM related with the DNBR will be DNB_MIN that is the minimum of the DNBR at any location and at any time of the transient. The fuel temperature safety variable FUELT has a related FOM called herein FUELT_MAX, which is the maximum fuel temperature at any location and at any time of the 
transient, whose safety limit for category 2 is $2863 \mathrm{~K}$.

The next barrier is the primary system of the plant and the safety variable proposed is the pressurizer pressure (PRZP). The associated FOM is the maximum pressure reached in the pressurizer, called herein PRZP_MAX, and the safety limit for category 2 is $18.9 \mathrm{MPa}$.

The last barrier considered is the containment and the safety variable proposed is the leakage at the containment (CONTL), where the corresponding FOM is the maximum containment leakage, called herein CONTL_MAX, with a safety limit of $0.2 \%$ for category 2 .

\subsection{Identification of relevant phenomena and selection of appropriate $\mathrm{TH}$ parameters}

Steps 3 and 4 of the EBEPU approach are similar to their equivalents in the traditional BEPU approach for selecting the $\mathrm{TH}$ parameters that represent relevant physical phenomena associated to a LOFW [24-26]. In order to select the relevant $\mathrm{TH}$ parameters in this example of application, the guidance provided in PREMIUM work [27] has been followed. They are presented together with their nominal value and associated $p d f$ in section 3.6.

\subsection{Identification of relevant safety systems and components/trains}

Steps 5 and 6 of the EBEPU approach consist of the identification of relevant safety systems that take part in the progression of the particular sequence belonging to the accident scenario LOFW under study. Normally, each safety system consists normally of a number of redundant trains or components. As one can observe in Fig. 2, the progression of the accident scenario through the only sequence considered in this paper, i.e. sequence \#1, involves successful actuation of the safety functions FT1 to FT5 presented in Table 2. It provides information on the safety function name, its success criteria involving the trains/components (TC) of the safety systems that perform the safety function and the name of the relevant TCij. 
Table 2. Safety functions and success criteria required for LOFW. Relevant trains/components functions.

\begin{tabular}{llll}
\hline Header & $\begin{array}{l}\text { Safety } \\
\text { Function }\end{array}$ & Success Criteria & TCij \\
\hline FT1 & RPS & Two RPS channels & K \\
\hline FT2 & AFWS & 1/3 AFW trains & AFW1, AFW2, AFW3 \\
\hline FT3 & PRZ-opens & 1/2 PORV or 1/3 SV open (o) & PORV1o, PORV2o, SV1o, SV2o, SV3o \\
\hline FT4 & PRZ-closes & 2/2 PORV and 3/3 SV close (c) & PORV1c, PORV2c, SV1c, SV2c, SV3c \\
\hline FT5 & 2SG-closes & 3/3 MSIV or 8/8 SD close (c) & SD1c, SD2c, SD3c, SD4c, SD5c, SD6c, SD7c, \\
& & & SD8c, MSIV1c, MSIV2c, MSIV3c \\
\hline FT6 & IHI & 1/3 IHI trains & IHI1, IHI2, IHI3 \\
\hline FT7 & FB & 1/2 PORVm \& 1/3 FBIHI & PORV1mo, PORV2mo, FBIHI, FBIHI2, FBIHI3 \\
\hline FT8 & IHR & 1/3 IHR trains & IHR1, IHR2, IHR3
\end{tabular}

\subsection{TH model description}

A typical 3-loop PWR NPP has been modeled for TRACE code and ran with version V5.0 Patch 4 using the SNAP suite to simulate the transient corresponding to sequence \#1 (step 7). The model consists of two thermal hydraulic systems linked: primary and secondary systems, as shown in Figures 3 and 4 respectively.

The primary system includes a tridimensional component type VESSEL, which represents the reactor pressure vessel including the core, three independent reactor coolant loops, three primary side steam generators ( $3 \mathrm{SG}$ ), one pressurizer (PRZ) and three reactor coolant pumps. Reactor core consists of fuel elements of $15 \times 15$ rods divided into two groups. One group models the average power and another group, which is the most unfavorable fuel element, models the peak power of the hot channel. Average power elements are associated to the coolant cells of the VESSEL element (in radial sector 1, axial levels 3 to 8), while hot channel is modeled apart through a one-dimensional PIPE component connected to the entrance and exit of the core.

In addition, safety systems supporting the primary system have been modeled: three trains corresponding to the high pressure injection and recirculation system (3 IHI and 3 IHR respectively) connected to the RCS (reactor coolant system), and 2 PORV and 3 SV connected to the PRZ.

The secondary system includes three secondary side steam generators (3 SG), associated each 
with the corresponding cooling loops in the primary system, and three FILLS representing the main feed water system ( $3 \mathrm{MFW}$ ). It also includes turbine group and steam dump valves ( 8 SD valves).

In addition, safety systems supporting the secondary system have been modeled: three redundant auxiliary feed water trains ( $3 \mathrm{AFW}$ ), three main steam isolation valves (3 MSIV), three relief valves (3 RV) and fifteen safety valves (3 groups of 5 SSV valves). 

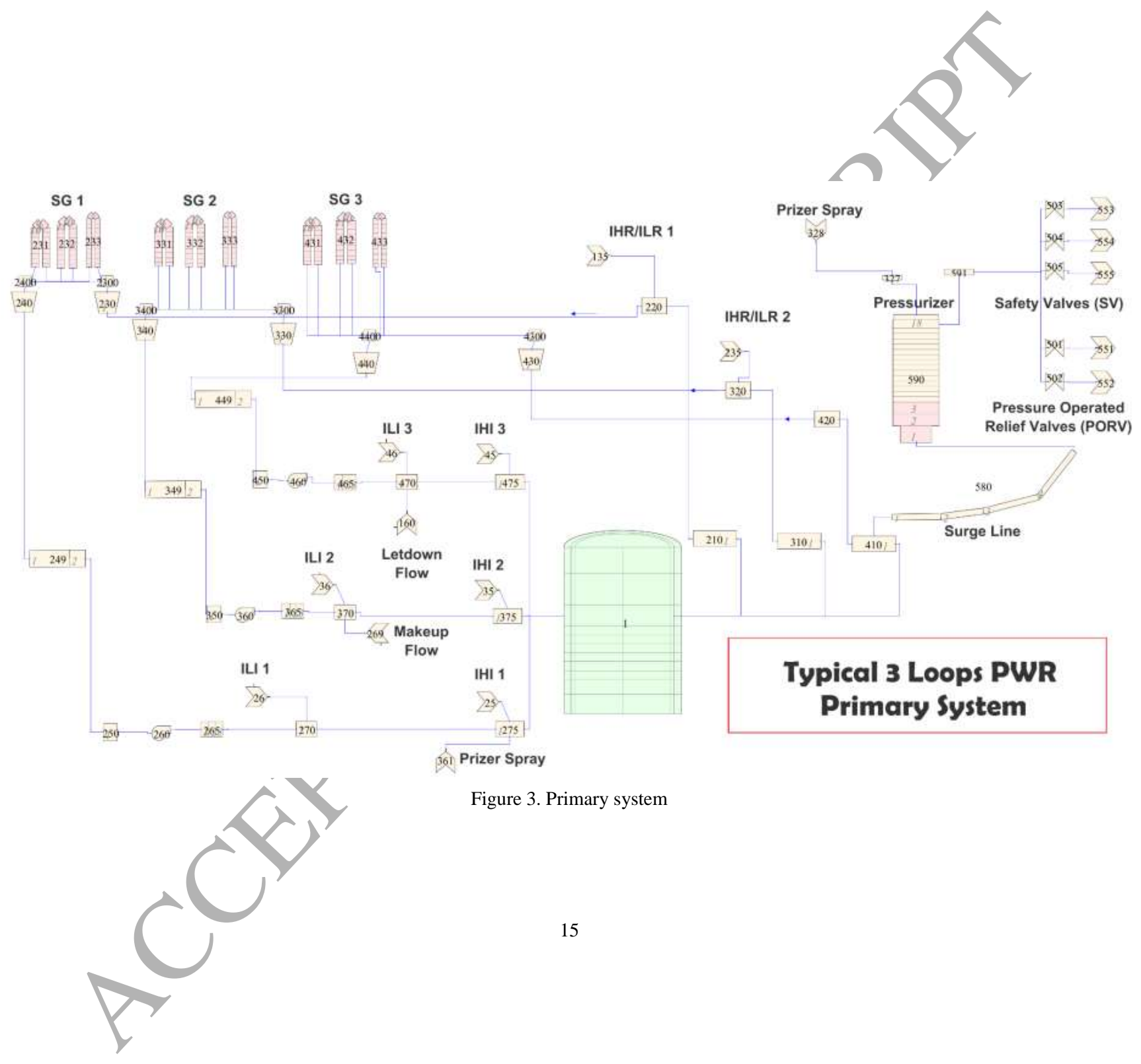

Figure 3. Primary system 


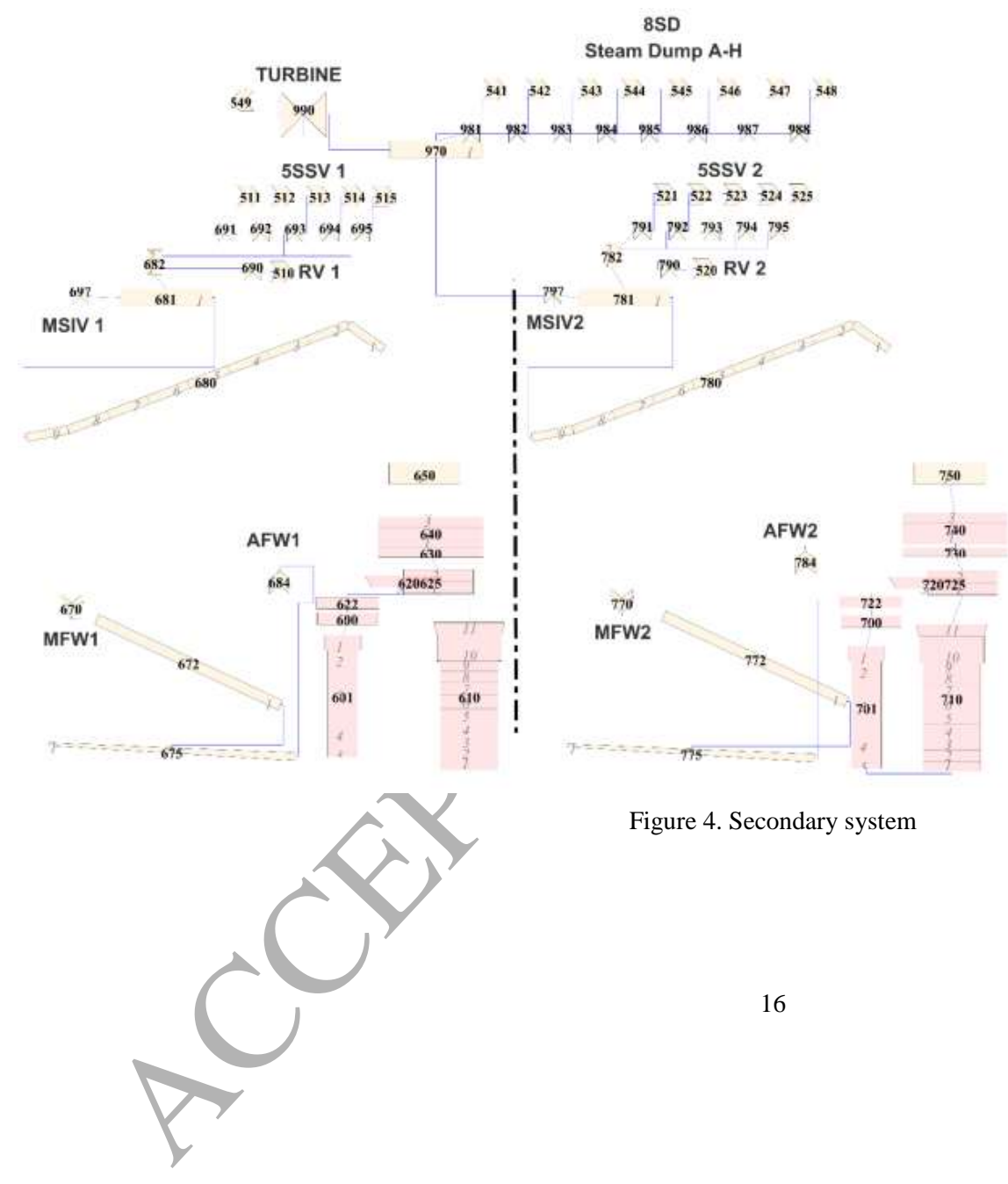

\section{Typical 3 Loops PWR \\ Secondary System}

5SSV 3

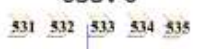

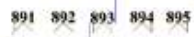

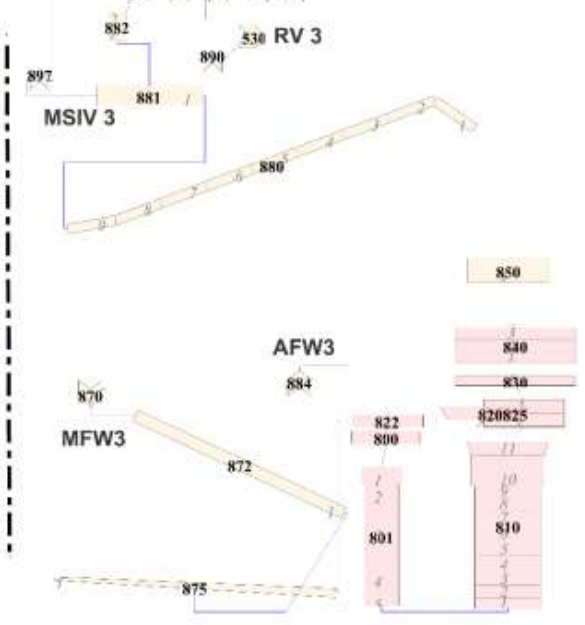

Figure 4. Secondary system 


\subsection{TH parameters. Initial and boundary conditions. Uncertainties}

Simulation of sequence \#1 using the TH model requires realistic input and uncertainty, if applicable, associated with TH parameters (step 8). Table 3 shows initial and boundary conditions for primary and secondary loops and, if considered, their corresponding uncertainty parameters adopted in this example of application [26, 27].

Table 3. Initial and boundary conditions for the primary and secondary systems

\begin{tabular}{|c|c|c|c|}
\hline Parameter & Units & Ref. Value & Uncertainty \\
\hline Thermal Power & MW & 2686.0 & INPOW \\
\hline Hot Channel Peak Power & $(-)$ & $+20^{c}$ & PEAKF \\
\hline Pressurizer Pressure & $\mathrm{MPa}$ & 15.6 & - \\
\hline Hot Channel Temperature & $\mathrm{K}$ & 618.0 & - \\
\hline Hot Leg Temperature & $\mathrm{K}$ & 604.8 & - \\
\hline Cold Leg Temperature & & 564.3 & - \\
\hline Average Temperature & & 584.54 & - \\
\hline Pressurizer Temperature & & 618.43 & - \\
\hline Rod Outside Diameter & $\mathrm{mm}$ & 9.48 & - \\
\hline Pressure Loss in the core & $\mathrm{kPa}$ & 250 & - \\
\hline Mass Flow Rate in the primary & $\mathrm{kg} / \mathrm{s}$ & 12700 & - \\
\hline Pressurizer Level & M & 7.22 & - \\
\hline Steam Generators & $\mathrm{MPa}$ & 6.86 & - \\
\hline Steam Generators outlet Temperature & $\mathrm{K}$ & 557.60 & - \\
\hline Steam Generators inlet Temperature & $\mathrm{K}$ & 499.00 & - \\
\hline Steam Generators Pressure Loss & $\mathrm{kPa}$ & 20 & - \\
\hline Steam Generators Level (NR) & $\%$ & 50.60 & - \\
\hline Mass Flow Rate by Steam Generator & $\mathrm{kg} / \mathrm{s}$ & 475.00 & - \\
\hline Fuel Thermal Conductivity & $\mathrm{W} / \mathrm{mK}$ & Table $^{1}$ & UO2TC \\
\hline
\end{tabular}

${ }^{1}$ Fuel Thermal Conductivity Vs Temperature Table

In addition, Table 4 shows relevant conditions for operation (e.g. set points) for the simulation of the transient corresponding to sequence \#1 using the TH model and, if applicable, the associated uncertainty parameter. 
Table 5 shows the description of the $p d f$ adopted to represent uncertainty of the parameters considered in this case study.

Table 4. Relevant conditions for operation

\begin{tabular}{llll}
\hline Parameter & Units & Ref. Value & Uncertainty \\
\hline Level set point in SGs for SCRAM signal & $\%$ & 17.6 & SCRSG \\
\hline Delay to reactor SCRAM & $\mathrm{S}$ & 0 & SCRTO \\
\hline Residual power multiplier & $\mathrm{MW}$ & Table & RPOWM \\
\hline Delay to start AFWS pumps & $\mathrm{s}$ & 0 & AAATO \\
\hline AFWS flow temperature & $\mathrm{K}$ & 293.15 & AAATI \\
\hline AFWS flow rate & $\mathrm{kg} / \mathrm{s}$ & 24.28 & AAAQI \\
\hline Delay to open Steam Dump valves & $\mathrm{s}$ & 0 & - \\
\hline Pressure set point secondary RV valves & $\mathrm{MPa}$ & 7.7 & - \\
\hline Pressure set point secondary SSV valves & $\mathrm{MPa}$ & 8.1 & - \\
\hline Pressure set point primary PORV valves & $\mathrm{MPa}$ & 16.03 & PRPRV \\
\hline Pressure set point primary SV valves & $\mathrm{MPa}$ & 17.13 & PRPSV \\
\hline Delay to close PORV and SV valves & $\mathrm{S}$ & 0 & VCLTO \\
\hline 2 Residual Power Vs Time Table & M & &
\end{tabular}

Table 5. Description of uncertainty parameters

\begin{tabular}{lllllll}
\hline Parameter & Parameter type & Distribution type & Min & Max & Mean & Std. \\
& & & & & & Dev. \\
\hline INPOW & Multiplicative & Normal & 0.98 & 1.02 & 1 & 0.01 \\
\hline UO2TC & Multiplicative & Normal & 0.9 & 1.1 & 1 & 0.05 \\
\hline PEAKF & Multiplicative & Normal & 0.95 & 1.05 & 1 & 0.025 \\
\hline SCRSG & Multiplicative & Uniform & 0.95 & 1.05 & NA & NA \\
\hline SCRTO & Additive & Uniform & 0 & 27 & NA & NA \\
\hline RPOWM & Multiplicative & Normal & 0.92 & 1.08 & 1 & 0.04 \\
\hline AAATO & Additive & Uniform & 0 & 197 & NA & NA \\
\hline AAATI & Additive & Uniform & -2 & 2 & NA & NA \\
\hline AAAQI & Multiplicative & Normal & 0.95 & 1.05 & 1 & 0.025 \\
\hline PRPRV & Additive & Uniform & -0.2 & 0.2 & NA & NA \\
\hline PRPSV & Additive & Uniform & -0.2 & 0.2 & NA & NA \\
\hline VCLTO & Additive & Uniform & 0 & 180 & NA & NA
\end{tabular}




\subsection{Identification of relevant configurations of safety systems and their probabilities}

In developing the EBEPU approach, simulation of sequence \#1 using the TH model requires not only realistic input and uncertainty associated with TH parameters (initial and boundary condition and other TH parameters), but also realistic input on available safety systems configuration (step 9).

As introduced in section 3.4 (see also Fig. 2), progression of the accident scenario considered in this paper, i.e. sequence \#1, involves successful actuation of several safety functions, which must be performed by at least one of several redundant trains/components that táke part of each safety system responsible for developing the corresponding safety function (see Table 2).

Martorell et al., 2017 [17] presents a practical approach to identify relevant configurations of safety systems and to assess the associated occurrence probability of such configurations using PSA results of a NPP. The most relevant configurations mean the most probable ones according to PSA-based probabilistic models and data, which incorporate best estimate assumptions on the availability of safety systems. The PSA available for developing this case study includes the above event tree (Fig. 2) and the fault trees required to represent the unavailability (or availability) of the safety system trains/components that take part of the safety functions involved in this event tree (see headers in the above event tree). The results obtained using the above approach are summarized in the following.

Let us consider the following vector $\boldsymbol{g}$ representing a generic group of equivalent configurations of availability/unavailability of the relevant Trains/Components. One realization of vector $\boldsymbol{g}$ will represent a particular group. The above vector contains 12 variables, $\mathrm{TC}_{\mathrm{ij}}$, where each one can take a value ranging in the interval given in the corresponding/TCij in Table $2\{0-1,0-3,0-2,0-3,0-2,0-3,0-8,0-3,0-3,0-3,0-2,0-3\}$.

$\boldsymbol{g}=\{\mathrm{K}$, AFWS, PORVo, SVo, PORVc, SVc, SDc, MSIVc, IHI, FBIHI, PORVmo, IHR $\}$

Table 6 shows only the 16 most relevant groups of equivalent configurations, i.e. the most probable, out of the 507 groups found of about 8 million groups of possible configurations based on enumeration of combinations of the 12 variables in vector $g$. The most relevant groups of configurations represent a cumulative probability of 0,9905 and all of them belong 
to the accident scenario \#1 under study. In Table 6, every configuration is represented by a set of numbers ranging each one between 0 and MAX, where MAX represents the maximum number of train/component redundancies according to Table 2.

Table 6. List of groups of equivalent configurations of safety systems, $g_{m}$, and probabilities, $\mathbf{P}\left(g_{m}\right)$.

\begin{tabular}{|c|c|c|c|c|c|c|c|c|c|c|c|c|c|c|}
\hline 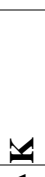 & $\frac{3}{4}$ & : & $i_{0}^{\circ}$ & : & $\sum_{n}^{0}$ & ڤั & $\sum_{i}^{0}$ & 畐 & 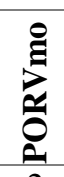 & 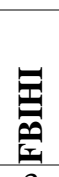 & 䓫 & $\begin{array}{c}\text { Accident } \\
\text { scenario } \\
\#\end{array}$ & $\mathbf{P}\left(g_{m}\right)$ & $\begin{array}{l}\text { Cumulative } \\
\text { probability }\end{array}$ \\
\hline 1 & 3 & 2 & 3 & 2 & 3 & 8 & 3 & 3 & 2 & 3 & 3 & 1 & 7,831E-01 & $7,831 \mathrm{E}-01$ \\
\hline 1 & 2 & 2 & 3 & 2 & 3 & 8 & 3 & 3 & 2 & 3 & 3 & 1 & $1,110 \mathrm{E}-0$ & $8,941 \mathrm{E}-01$ \\
\hline 1 & 3 & 2 & 3 & 2 & 3 & 7 & 3 & 3 & 2 & 3 & 3 & 1 & 2,004E-02 & $9,142 \mathrm{E}-01$ \\
\hline 1 & 3 & 2 & 3 & 2 & 3 & 8 & 3 & 3 & 0 & 0 & 3 & 1 & $1,743 \mathrm{E}-02$ & $9,316 \mathrm{E}-01$ \\
\hline 1 & 3 & 2 & 2 & 2 & 3 & 8 & 3 & 3 & 2 & 3 & 3 & & $1,463 \mathrm{E}-02$ & $9,462 \mathrm{E}-01$ \\
\hline 1 & 3 & 2 & 3 & 2 & 3 & 8 & 3 & 3 & 2 & 3 & 0 & & $1,021 \mathrm{E}-02$ & 9,564E-01 \\
\hline 1 & 3 & 1 & 3 & 2 & 3 & 8 & 3 & 3 & 2 & 3 & J & & $6,760 \mathrm{E}-03$ & $9,632 \mathrm{E}-01$ \\
\hline 1 & 1 & 2 & 3 & 2 & 3 & 8 & 3 & 3 & 2 & 3 & & & $5,319 \mathrm{E}-03$ & $9,685 \mathrm{E}-01$ \\
\hline 1 & 3 & 1 & 3 & 2 & 3 & 8 & 3 & 3 & 1 & 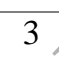 & & 1 & $4,521 \mathrm{E}-03$ & $9,730 \mathrm{E}-01$ \\
\hline 1 & 3 & 2 & 3 & 2 & 3 & 8 & 0 & 3 & 2 & 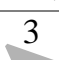 & & 1 & $3,828 \mathrm{E}-03$ & $9,769 \mathrm{E}-01$ \\
\hline 1 & 2 & 2 & 3 & 2 & 3 & 7 & 3 & 3 & 2 & & $y$ & 1 & $2,798 \mathrm{E}-03$ & $9,797 \mathrm{E}-01$ \\
\hline 1 & 2 & 2 & 3 & 2 & 3 & 8 & 3 & 3 & 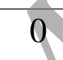 & 0 ) & 3 & 1 & $2,475 \mathrm{E}-03$ & $9,821 \mathrm{E}-01$ \\
\hline 1 & 3 & 2 & 3 & 2 & 3 & 0 & 3 & 3 & 2 & 3 & 3 & 1 & $2,445 \mathrm{E}-03$ & $9,846 \mathrm{E}-01$ \\
\hline 1 & 3 & 2 & 3 & 2 & 3 & 8 & 2 & 3 & 2 & 3 & 3 & 1 & $2,349 \mathrm{E}-03$ & $9,869 \mathrm{E}-01$ \\
\hline 1 & 2 & 2 & 2 & 2 & 3 & 8 & & 3 & 2 & 3 & 3 & 1 & 2,083E-03 & $9,890 \mathrm{E}-01$ \\
\hline 1 & 2 & 2 & 3 & 2 & 3 & & & & 2 & 3 & 0 & 1 & $1,472 \mathrm{E}-03$ & $9,905 \mathrm{E}-01$ \\
\hline
\end{tabular}

For sake of comparison between EBEPU and BEPU approaches, note that under the traditional BEPU approach, only the most conservative configuration belonging to accidental sequence \#1 would have been considered instead of the array of configurations shown in Table 6 . This conservative configuration would be the worst one leading to accident sequence \#1 consisting of: successful reactor scram $(\mathrm{K})$, one of three AFW trains is available and just one valve of SGs secondary side opens, two PORVs are unavailable, one of three SV is available, which is the only one available to close, and all three MSIV close. Consequently, there is no need to operate IHI, IHR, PORVm nor FBIHI. This very conservative configuration is associated group $\mathrm{g}_{\mathrm{wors}}=\{1,1,0,1,-, 1,-, 3,-,-,-,-\}$, which has a very low occurrence probability of $6.3 \mathrm{E}-07$, which has been obtained directly from the PSA available. This probability is almost four orders of magnitude lower than the probability of the realistic configuration with the lowest probability in Table 6 . 


\section{RESULTS}

This section summarizes the results of the application of the EBEPU approach proposed in Section 2 using the TRACE code and the models and data introduced in previous Section 3.

It encompasses with steps 10 to 12 of the EBEPU methodology proposed in this paper. A sample size of $\mathrm{N}=59$ is adopted to obtain the one sided STL 95/95 using Wilks' method. First, sampling of system configurations and TH parameters is needed (step 10). Thus, a sample of 59 system configurations taken from Table 6 is generated by importance sampling depending on the probability of each system configuration. In addition, a random sample of 59 sets of parameters taken from their $p d f s$ in Table 5 adopting pure Monte Carlo method is generated, which permits to obtain a sample of 59 sets of TH parameters from Tables 3 and 4 . Notice, some TH parameters remain constant at their reference value in Tables 3 and 4 for the 59 sets since they are not associated an uncertainty parameter. One realization of the above system configurations and one set of TH parameters is used to built one input to the TRACE code. This procedure is repeated to built $\mathrm{N}$ input files to TRACE. Next, 59 computer runs are performed to simulate accidental scenario \#1 to obtain 59 evolutions of the safety variables and 59 values for each FOM. Next step consist of processing results of FOMs obtained after performing $\mathrm{N}$ simulations with the computer code (step 11). Herein, FOS (first order statistics) is adopted based on the application of the Wilks' formulae to verify compliance of safety criteria (step 12). So that, the maximum value found after 59 simulations is adopted for each FOM to verify compliance with the safety limit.

In addition, the results found with the EBEPU method are compared with equivalent results derived adopting the BEPU approach.

\subsection{Base case simulation}

Simulation of accidental scenario \#1 starts with the coast down of the steam generators main feed water pumps at $\mathrm{t}=100 \mathrm{~s}$, diminishing the capability of the secondary system to remove primary heat. Consequently, the water level of the steam generators abruptly plunges activating the SCRAM signal. In addition, auxiliary feed water pumps start restoring the capability the secondary system to remove primary heat after SCRAM. However, primary pressure starts increasing early in the transient. Thus, primary pressure may increase up to 
reach PORVs valves rated pressure that opens (alternatively, SVs must open in case of PORVs failure). Once pressure has decreased latter on during the transient, primary relief or safety valves close and the plant goes to OK state.

\subsection{Results under the EBEPU approach}

In simulating the accidental sequence \#1, the EBEPU approach considers realistic configurations of the safety systems availability based on the results of sampling from Table 6 . Therefore, each particular configuration assumes a priori some trains/components are available. However, this only means the train/component is free of hardware failures when it is sampled to be available (operable a priori), however, even so, the train/component may be operable or not (a posteriori) depending on the TH conditions arising) during the transient simulation. These conditions affecting trains/components operability are also monitored to decide on the component operability at any given time during the transient simulation.

Figures 5 to 7 show the evolution of the safety variables selected under the EBEPU approach. It is important to realize although there are four safety variables (and corresponding FOMs) in Table 1, only three FOMs are considered and their corresponding safety variables are represented in these figures. The reason is that there is no sense to represent the CHF because of the heat-transfer regime for fuel rods is liquid single phase heat-transfer at any time for all the transients and therefore critical heat flux conditions are not reached. 


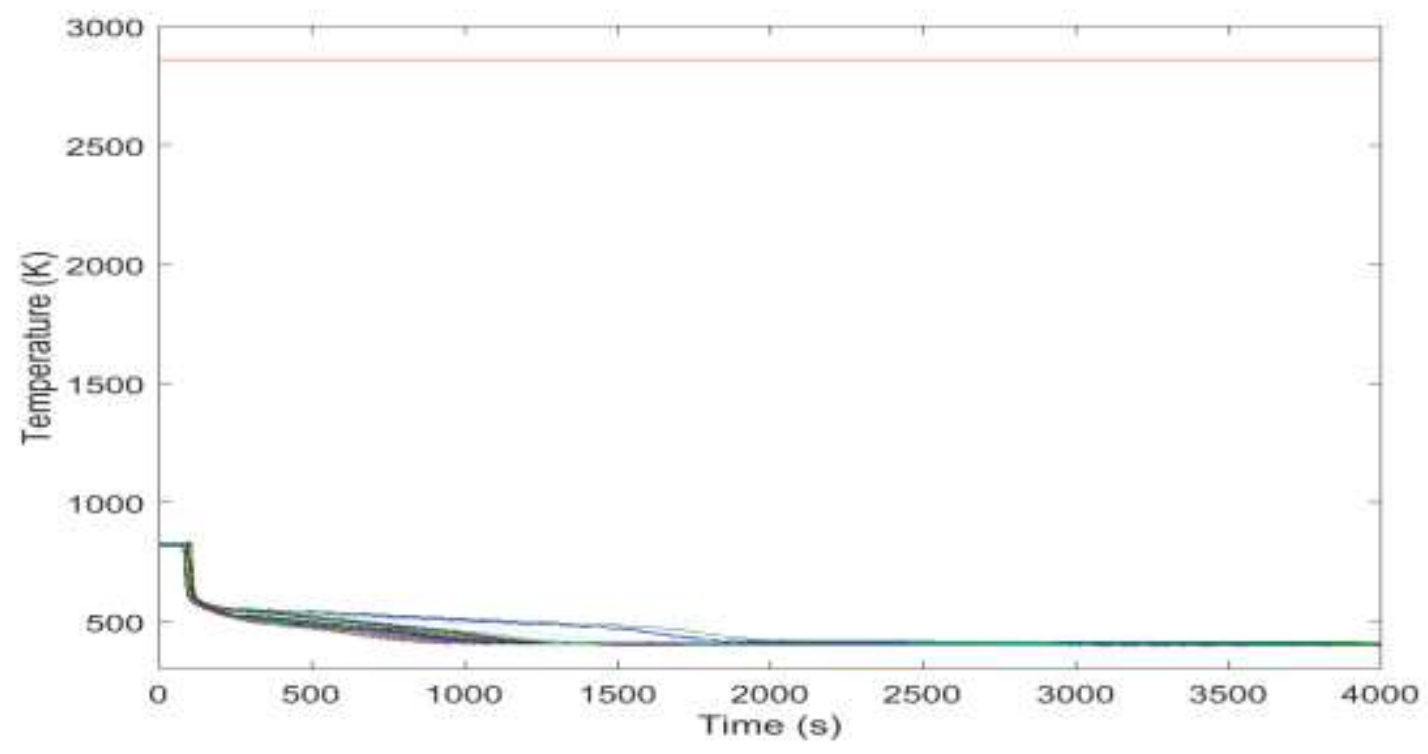

Figure 5. Evolution of FUELT in sequence \#1 for the EBEPU approach

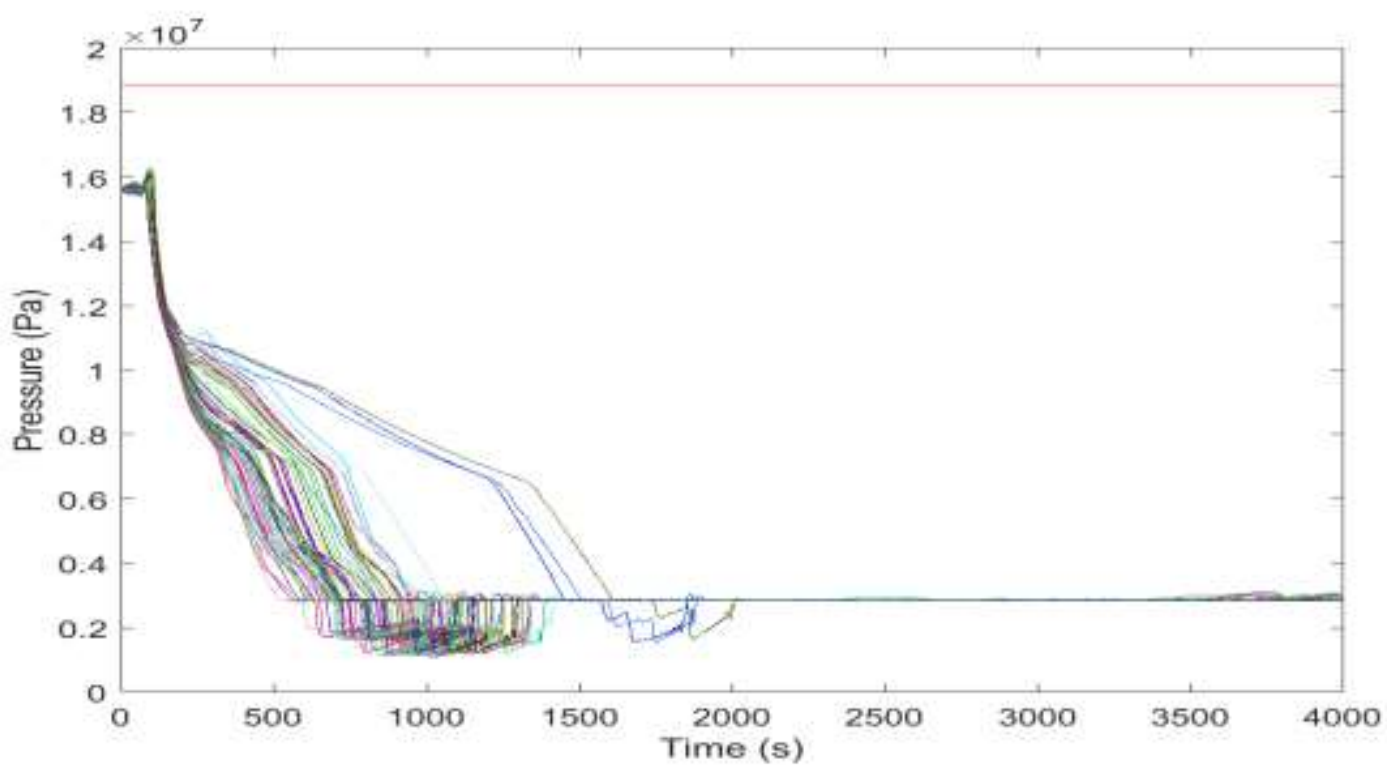

Figure 6. Evolution of PRZP in sequence \#1 for the EBEPU approach 


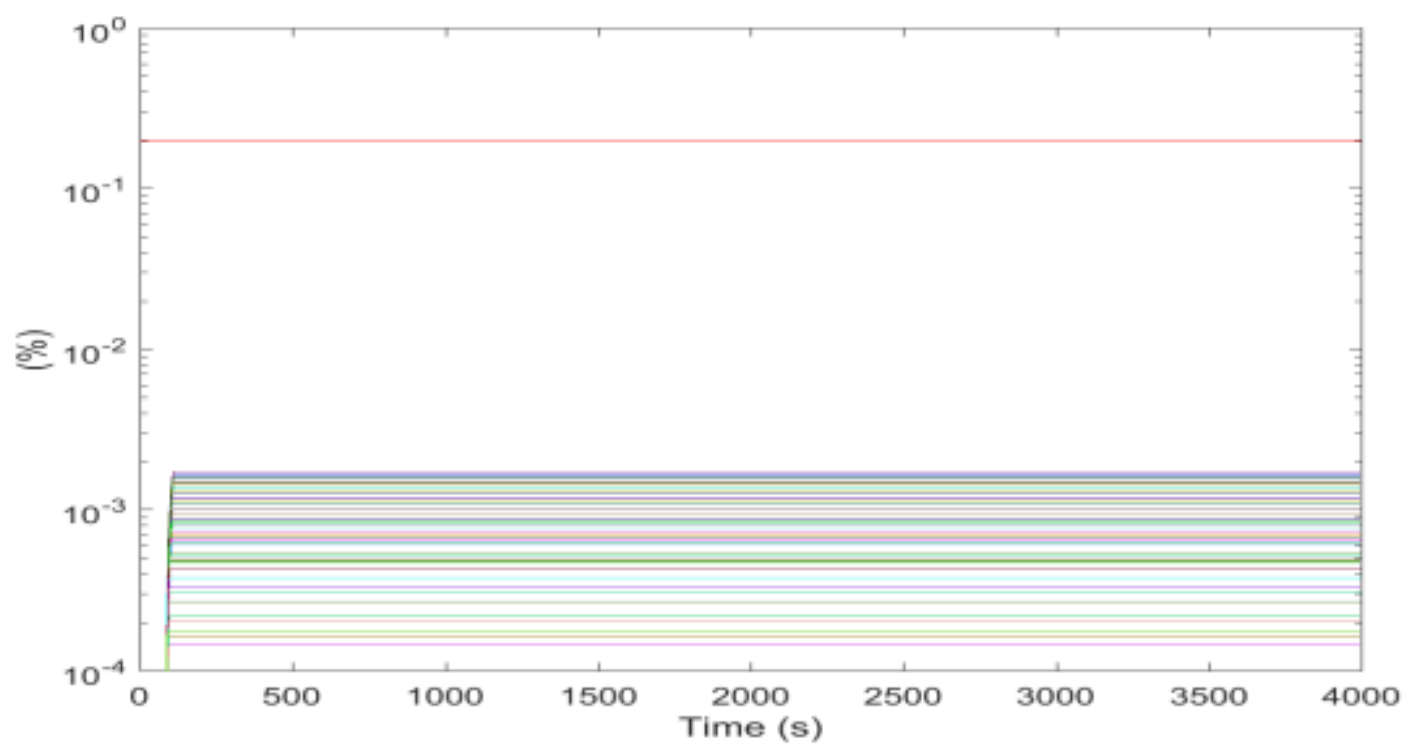

Figure 7. Evolution of CONTL in sequence \#1 for the EBEPU approach

The application of the EBEPU approach to this example of application shows that looking at Figures 5 to 7 the evolution of the safety variables of interest and the corresponding FOMs remain far below their safety limits. Thus, the maximum values of FUELT_MAX, PRZP_MAX and CONTL_MAX are below the corresponding safety limits shown in Table 1 . Based on it, one may conclude that accident sequence \#1 fulfils all the acceptance limits with appropriate safety margin and, therefore, the safety criteria are met in this example of application.

\subsection{Comparison of results between the EBEPU and BEPU approaches}

This section presents the results found for the same example of application adapted to follow the BEPU approach. The main difference as compared to the EBEPU approach is the adoption now of a unique and conservative assumption of safety systems availability, which remains the same for the $\mathrm{N}$ computer runs, instead of obtaining a sample of 59 system configurations selected from Table 6 by importance sampling depending on the probability of each system configuration. This very conservative configuration, represented by $\mathrm{g}_{\mathrm{worst}}=\{1,1,0,1,-, 1,-, 3,-,-,--$ $,-\}$ has a very low occurrence probability of $6.3 \mathrm{E}-07$, which has been obtained directly from the PSA available. 
In addition, a sample of 59 sets of parameters taken from their pdfs in Table 5 is generated, which permits to obtain a sample of 59 sets of TH parameters from Tables 3 and 4 . The above conservative assumption on systems availability and one set of $\mathrm{TH}$ parameters is used to built one input to the TRACE code. This procedure is repeated to built $\mathrm{N}$ input files to TRACE. Next, 59 computer runs are performed to simulate accidental scenario \#1 to obtain 59 evolutions of the safety variables and 59 values for each FOM. Next step consist of processing results of FOMs obtained after performing $\mathrm{N}$ simulations with the computer code (step 11). Herein, FOS (first order statistics) is adopted based on the application of the Wilks' formulae to verify compliance of safety criteria (step 12). So that, the maximum value found after 59 simulations is adopted for each FOM to verify compliance with the safetylimit.

Figure 8 shows again the evolution of the primary pressure PRZP obtained now under the BEPU approach. Only the evolution of this PRPZ has been plotted as there are no significant differences between adopting the EBEPU or BEPU approaches for the rest of safety variables and FOMs (Figures 5 and 7) in this particular example of application.

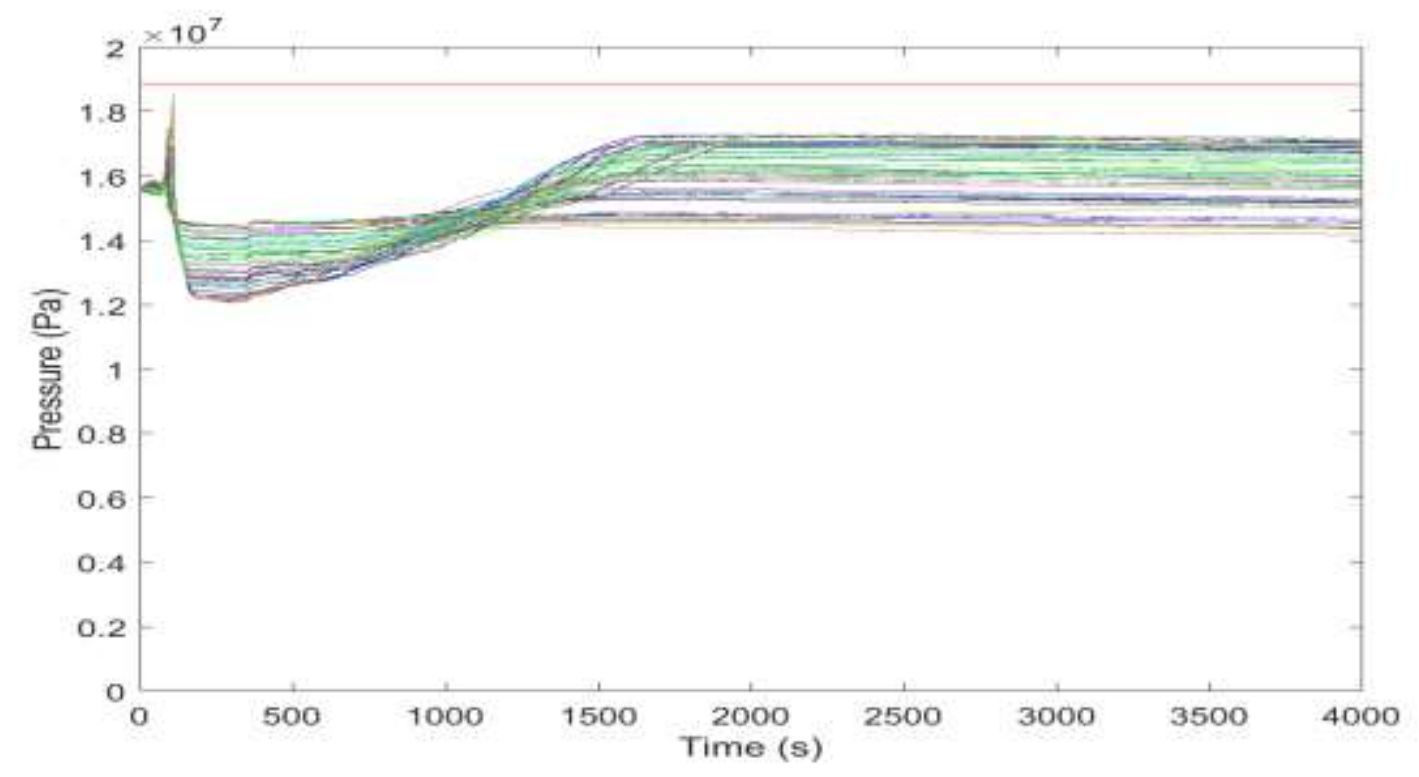

Figure 8. Evolution of PRZP in sequence \#1 for the BEPU approach

Figure 8 shows the primary pressure remains below but close to the safety limit in many of the 59 simulations, i.e. PRZP_MAX is below and close its safety limit. Therefore, because of we are using a STL 95/95 and the FOS of PRZP_MAX to verify compliance of acceptance criterion, this result indicates the acceptance criterion is met, i.e. PRZP_MAX is below the 
safety limit with STL 95/95. Therefore, accident sequence \#1 would also fulfill the safety criteria in this example of application under the traditional BEPU approach but with a reduced safety margin for safety variable PRZP.

Comparing Figure 6 (EBEPU approach) with corresponding Figure 8 (BEPU approach), one can realize the evolution of primary system pressure PRZP is quite different under both approaches as a consequence of the different assumptions on safety systems availability. In the former case, i.e. adopting realistic assumptions on the safety systems availability, the PRZP_MAX is low and PRZP goes to a very low pressure of the RCS in the steady-state reached in the long term of the accident progression. On the contrary, adopting conservative assumptions on safety systems availability, the PRZP_MAX is high and it may go very close to the safety limit, while the PRZP goes to a very high pressure of the RCS in the steady-state reached in the long term of the accident progression. 


\section{CONCLUDING REMARKS}

The results of the example of application demonstrate that it is possible the extension of traditional BEPU approaches departing from the results available in the NPP Safety Analysis (deterministic and probabilistic analyses), which can be integrated in a natural way adopting the EBEPU procedure proposed in Section 2.

In this example of application, the safety criteria are met under both EBEPU and BEPU approaches, despite of a FOM is very close to one safety limit in some simulation under the BEPU approach adopting a STL 95/95. However, there are important differences what concerns PRZP evolution. The EBEPU approach provides a more realistic situation while the BEPU approach presents a more conservative one, which may not be a realistic situation to be taken into account for transient evolution management.

In addition, this situation may one think that for other less frequent and more hazardous accidental sequences the safety criteria could not be accomplished under the BEPU approach (more conservative) while safety criteria could be met under the EBEPU approach (more realistic and less conservative). Thus, adopting súch unrealistic safety system configurations could make one conclude the design is inappropriate to manage such accident sequence when its occurrence probability is by far yery low and unrealistic with such a conservative configuration of safety systems availability.

Another important situation that one could envisage is that in spite of the most conservative assumptions on safety systems availability would yield most likely to the worst plant conditions, there is no evidence that this situation will be found always. So that, for planning and management of accident scenarios, e.g. emergency procedures development and operators training, one should identify and face those accident scenarios which are both realistic and dangerous, and the implementation of the EBEPU approach can be of help to this purpose . 


\section{ACKNOWLEDGMENTS}

This research work has been supported by CSN (Consejo de Seguridad Nuclear) under contract SIN/4078/2013/640.

This work has been developed partially with the support of Programa de Apoyo a la Investigación y Desarrollo of the Universitat Politècnica de València (PAID UPV).

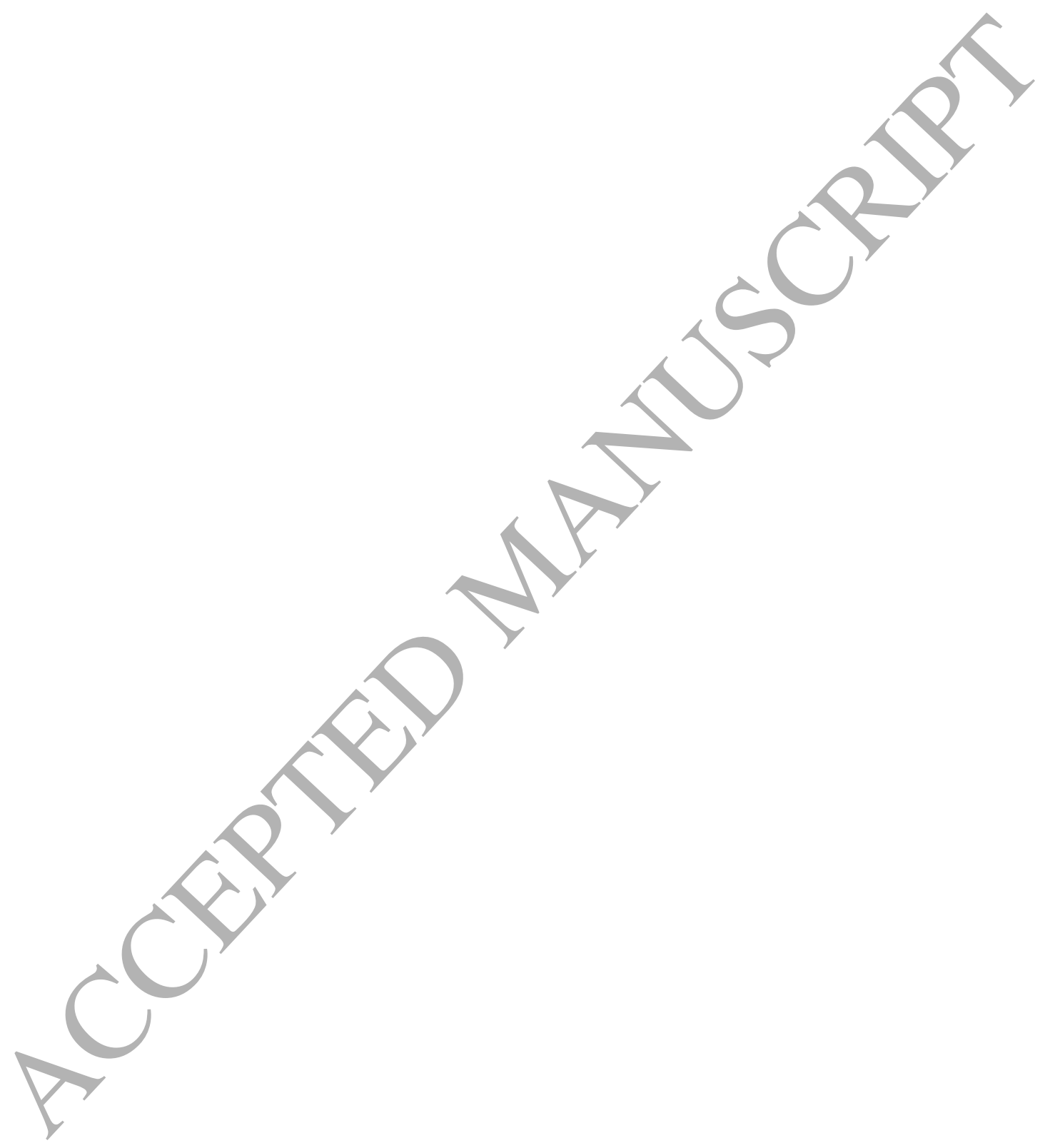




\section{REFERENCES}

[1] International Atomic Energy Agency (IAEA), Safety Assessment for Facilities and Activities, General Safety Requirements No. GSR Part 4 (Rev. 1), Vienna, 2016.

[2] Zio E., Integrated deterministic and probabilistic safety assessment: Concepts, challenges, research directions, Nuclear Engineering and Design, 280: 413-419, 2014.

[3] Gonzalez-Cadelo J., Queral C., Montero-Mayorga J., Analysis of cold leg LOCA with failed HPSI by means of integrated safety assessment methodology, Annals of Nuclear Energy 69: 144-167, 2014.

[4] Kang D.G., Ahn S., Chang S.H, A combined deterministic and probabilistic procedure for safety assessment of beyond design basis accidents in nuclear power plant: Application to ECCS performance assessment for design basis LOCA redefinition, Nuclear Engineering and Design, 260 :165-174, 2013.

[5] International Atomic Energy Agency (IAEA), Deterministic Safety Analysis for Nuclear Power Plants, Specific Safety Guide No. SSG-2, Vienna, 2009.

[6] International Atomic Energy Agency (IAEA), Deterministic Safety Analysis for Nuclear Power Plants, Specific Safety Guide DS491 No. SSG-2. Rev. 1, Vienna, 2016.

[7] Dusic M., Dutton M., Gleaser H., Herb J., Hortal J., Mendizabal R., Pelayo F., Combining Insights from Probabilistic and Deterministic Safety Analyses in Option 4 from the IAEA Specific Safety Guide SSG-2, Nuclear Technology, 188: 63-77, 2014.

[8] Martorell S., Martón I., Lázaro A., Sánchez F., Villanueva J.F., Carlos S., Sánchez A., A procedure to develop the EBEPU methodology merging PSA-based assumptions and BEPU method. In Proceedings of the annual European Safety and Reliability Conference ESREL 2015, Zürich, Switzerland.

[9] Briggs, L.L., Uncertainty Quantification Approaches for Advanced Reactor Analyses, Argonne National Laboratory, Nuclear Engineering Division, Chicago, 2008

[10] Pourgol-Mohammad, M., 2009. Thermal-hydraulics system codes uncertainty assessment: a review of the methodologies. Annals of Nuclear Energy 36: 1774-1786.

[11] D'Auria, F., Camargo, C. \& Mazzantini, O. 2012. The Best Estimate Plus Uncertainty (BEPU) approach in licensing of current nuclear reactors. Nuclear Engineering and Design 248: 317-328.

[12] Wilsom, E.G., 2013. Historical insights in the development of best estimate plus uncertainty safety analysis. Annals of Nuclear Energy 52: 2-9.

[13] Unal, C., Williams, B., Hemez, F., Atamturktur, S.H. \& McClure, P. 2011. Improved best estimate plus uncertainty methodology, including advanced validation concepts, to license evolving nuclear reactors. Nuclear Engineering and Design 241: 1813-1833.

[14] Queral, C., Montero-Mayorga, J., Gonzalez-Cadelo, J. \& Jimenez, G. 2015. Large-Break LOCA BEPU analysis with TRACE code. Annals of Nuclear Energy 85: 576-589.

[15] Brown C,S., Zhan H., Kucukboyaci V., Sung Y. 2016. Best estimate plus uncertainty analysis of departure from nucleate boiling limiting case with CASL core simulator VERA-CS in response to PWR main steam line break event. Nuclear Engineering and Design 309: 8-22

[16] Pourgol-Mohammad, M., Mosleh A., Modarres M. 2010. Methodology for the use of experimental data to enhance model output uncertainty assessment in thermal hydraulics codes. Reliability Engineering and System Safety 95:77-86

[17] S. Martorell, P. Martorell, I. Martón, A.I. Sánchez, S. Carlos. An approach to address probabilistic assumptions on the availability of safety systems for deterministic safety analysis. Reliability Engineering and System Safety 160 (2017) 136-150

[18] TRACE 2014. TRACE v5.840 User's and theory manuals. Nuclear Regulatory Commission. 
[19] Wilks, S.S. 1941. Determination of sample sizes for setting tolerance limits. Annals of Mathematical Statistics 12 (1): 91-96.

[20] Beal, D. 2012. Sample size determination for a nonparametric upper tolerance limit for any order statistic. Paper SD-07, pp 1-8. Proceedings SESUG 2012

[21] McClymont A.S., Poehlman B.W., ATWS: A Reappraisal, Electric Power Research Institute EPRI NP-2230 Research Project, California, 1982.

[22] NEA 2005, Acceptance criteria and related safety margins. Task group on the Safety Margins Action Plan (SMAP).

[23] NUREG 2010. Analysis and Computational Predictions of CHF Position and Post-CHF Heat Transfer. International Agreement Report. NUREG/IA-0236.

[24] Reventós, F., Batet, L., Pretel, C., Ríos, M. \& Sol, I. 2007. Analysis of the Feed \& Bleed procedure for the Ascó NPP. First approach study for operation support. Nuclear Engineering and Design 237: 2006-2013.

[25] Precautions, Limitations \& Set-points. Westinghouse Electric Company LLC. REV. 21 August 2010.

[26] Perez et al. 2011. Uncertainty and sensitivity analysis of a LBLOCA in a PWR Nuclear Power Plant: Results of the Phase V of the BEMUSE programme. Nuclear Engineering and Design 241(10): 4206-4222.

[27] NEA, 2015, "Post-BEMUSE Reflood Model Input Uncertainty Methods (PREMIUM) Benchmark Phase II: Identification of Influential Parameters" Nuclear Safety NEA/CSNI/R(2014)14. 